\title{
Respuestas proactivas del gobierno surcoreano a la pandemia del coronavirus
}

\author{
South Korean Government's Proactive Responses to the Coronavirus Pandemic
}

Pan Suk Kim*

Resumen: Corea del Sur logró contener la propagación de la enfermedad del coronavirus sin imponer medidas de confinamiento ni restricciones serias de movilidad. El país adoptó un enfoque masivo y polifacético que incluyó el uso prácticamente universal de cubrebocas, distanciamiento social, pruebas de diagnóstico rápido, rastreo generalizado de alta tecnología y tratamiento efectivo de los infectados. Para difundir información sobre la emergencia y mantener el distanciamiento social generalizado, se usaron tecnologías avanzadas de información y comunicación. Gracias a las amplias pruebas de diagnóstico y al rastreo de alta tecnología, las autoridades sanitarias estuvieron equipadas para luchar contra el virus, que se movía con rapidez, y para rastrear intensivamente a las personas que pudieran haber estado expuestas a él. Así, la experiencia surcoreana en la implementación de estrategias de prueba, rastreo, aislamiento y tratamiento es una referencia útil para otros países que están lidiando con la pandemia.

Palabras clave: coronavirus, covid-19, respuestas gubernamentales, manejo de desastres, gobierno coreano.

Abstract: South Korea managed to contain the spread of the coronavirus disease without imposing a lockdown or serious restrictions to movement. The country adopted a massive, multipronged approach that included a near-universal use of face masks, social distancing, fast diagnostic testing, expansive high-tech tracing, and effective patient treatment of infected people. Advanced information and communication technologies were widely used in spreading emergency information and maintaining extensive social distancing. With expansive diagnostic tests and high-tech tracing, health officials were well armed to fight the fast-

*Pan Suk Kim es profesor de Administración Pública en el Departamento de Administración Pública Global, en la Facultad de Gobierno y Negocios de la Universidad de Yonsei, Campus Mirae, Woniu 26493, Corea del Sur. Tel: +82 33760 2341. Correo-e: pankim@gmail.com. orcID: https://orcid.org/0000-00020551-1702. Traducción del inglés de Ana Inés Fernández Ayala y Manlio F. Castillo Salas.

Artículo recibido el 24 de agosto de 2020 y aceptado para su publicación el 18 de enero de 2021.

DOI: http://dx.doi.org/10.29265/gypp.v30i2.877 
moving virus and aggressively track down people who may have been exposed. Thus, the South Korean experience with the implementation of test-trace-isolate-treat strategies serves as a helpful reference for other countries grappling with the pandemic.

Keywords: coronavirus disease, covid-19, governmental responses, disaster management, Korean government.

\section{INTRODUCCIÓN}

- 1 primer caso confirmado de coronavirus (covid-19) en Corea del Sur (de aquí 4 en adelante, Corea) se reportó el 20 de enero de 2020. Para el 19 de enero de 2021, el número total de casos infectados en Corea era de 72729 , con un total de 1264 muertos, mientras que a nivel global las cifras eran de 95 millones de infectados y más de 2 millones de muertos (Worldometer, 2021). En comparación, Estados Unidos tenía la mayor cantidad de casos confirmados (más de 24 millones), seguido por India (más de 10 millones), Brasil (más de 8 millones), Rusia (3 millones), Reino Unido (más de 3 millones), Francia, Turquía, Italia, Espańa, Alemania, Colombia, Argentina, México, Polonia, Sudáfrica, Irán, Ucrania y Perú, todos estos países con más de un millón de casos confirmados a partir del 19 de enero de 2021.

Para el 19 de enero de 2021, Estados Unidos había perdido más de 400000 personas por el covid-19, Brasil más de 200 000, India más de 150000 , México más de 140 000, el Reino Unido e Italia más de 80000 vidas cada uno, mientras que Francia había perdido a más de 70000 personas, Rusia 60 000, España e Irán contaban más de 50000 fallecidos cada uno, y Alemania, Colombia y Argentina sumaban, cada uno, más de 40000 decesos (Worldometer, 2021).

Corea implementó medidas de distanciamiento social el 29 de febrero de 2020, cuando comenzó el brote en el país. Se recomendó a las personas utilizar cubrebocas y abstenerse de salir de sus hogares, participar en reuniones masivas o reunirse con mucha gente en espacios cerrados, evitando los $3 \mathrm{C}:{ }^{1}$ lugares concurridos, contacto cercano y espacios confinados. El gobierno aconsejó al público quedarse en casa y emitió una orden administrativa para la suspensión de operaciones en los gimnasios interiores, instalaciones de entretenimiento, institutos educativos, instalaciones religiosas, y todas las demás actividades que requirieran reuniones grandes. También se implementaron medidas de control de la infección para grupos de alto riesgo, como los pacientes en sanatorios y hospitales mentales. Corea ganó confianza con estas medidas el 15 de abril, cuando aproximadamente 30 millones de personas participaron en las elecciones parlamentarias sin que se

${ }^{1}$ En inglés, las 3C corresponden a: crowded places, close-contact settings, y confined spaces (N. del T.). 
disparara un nuevo brote (Choe, 2020). El gobierno coreano ofrece diariamente sesiones informativas a través de los medios de comunicación y un sitio web exclusivo (Ministerio de Salud y Bienestar [MSB], 2021) sobre el covid-19, con estadísticas detalladas sobre pruebas, casos confirmados y fallecidos. Al hacerlo, el gobierno coreano ha transmitido a sus ciudadanos una impresión positiva sobre su competencia y transparencia en la respuesta a la pandemia del coronavirus.

Cada país tiene su propio contexto nacional, lo cual dificulta las comparaciones internacionales en materia del combate al covid-19. No obstante, la experiencia coreana ofrece lecciones útiles a la comunidad global. Este estudio es una referencia significativa para la comunidad internacional sobre la experiencia de Corea con el covid-19 y las medidas que el país ha tomado contra la pandemia en los últimos meses. El resto del texto se estructura de la siguiente forma: una breve visión general sobre la gestión de desastres, seguida de una exposición sobre medidas sanitarias y de cuarentena para el control de enfermedades infecciosas, una discusión sobre la gobernanza colaborativa y, por último, las conclusiones e implicaciones de política de este estudio.

\section{GESTIÓN DE CRISIS Y APRENDIZAJE INDUCIDO POR LA CRISIS}

Desastres recientes y brotes de enfermedades infecciosas han llevado a Corea a reconsiderar la importancia de estar preparados ante emergencias de salud pública. La primera obligación del gobierno es proteger la integridad física y la seguridad de sus ciudadanos cuando ciertos eventos perturban el funcionamiento normal de la sociedad. Durante desastres naturales, como terremotos, y catástrofes causadas por el hombre, como en el caso de apagones o incidentes similares, el Ministerio del Interior y Seguridad de Corea (MIS), como el organismo tradicional encargado de las emergencias nacionales, se responsabiliza por la seguridad de la población y la gestión de los desastres, y establece medidas de emergencia, así como acciones de prevención (Kim y Lee, 2014: 506-527; Farazmand, 2014). Sin embargo, en el caso de pandemias como la de covid-19, el MSB se encarga de gestionar la emergencia nacional y es responsable de coordinar y supervisar los asuntos y políticas relacionados con la salud y el bienestar de la población.

En otras palabras, el MIS maneja los desastres naturales, mientras que el MSB es responsable de las crisis sanitarias, incluida la pandemia por covid-19. Tanto el MIS como el MSB tienen sus propios manuales para hacer frente a las crisis. Según el Manual Estándar para la Gestión de Crisis por Enfermedades Infecciosas (Ministerio de Salud y Bienestar de Corea, 2014), hay cuatro niveles de alerta, según la gravedad de la crisis, la urgencia, la posibilidad de expansión de la 
CUADRO 1. Manual Estándar para la Gestión de Crisis por Enfermedades Infecciosas en Corea: cuatro niveles de alerta para enfermedades infecciosas

$$
\text { Nivel Contenido Acciones }
$$

\begin{tabular}{|c|c|c|}
\hline $\begin{array}{l}\text { Nivel 1: } \\
\text { Preocupación } \\
\text { (azul) }\end{array}$ & $\begin{array}{l}\text { Un nuevo brote de enfermedad infecciosa en el extranjero } \\
\text { y un paciente infectado por causa desconocida se reporta } \\
\text { en Corea. }\end{array}$ & $\begin{array}{l}\text { Monitoreo de signos y actividad, } \\
\text { comprobación de planes de } \\
\text { preparación. }\end{array}$ \\
\hline $\begin{array}{l}\text { Nivel 2: } \\
\text { Atención } \\
\text { (amarillo) }\end{array}$ & $\begin{array}{l}\text { Entrada al país de la nueva enfermedad infecciosa desde el } \\
\text { extranjero; una nueva enfermedad infecciosa o un rebrote } \\
\text { en Corea; notificación de la Organización Mundial de la } \\
\text { Salud de brotes de una enfermedad infecciosa. }\end{array}$ & $\begin{array}{l}\text { Operación del sistema } \\
\text { de cooperación entre } \\
\text { organizaciones relacionadas. }\end{array}$ \\
\hline $\begin{array}{l}\text { Nivel 3: } \\
\text { Alerta } \\
\text { (naranja) }\end{array}$ & $\begin{array}{l}\text { La nueva enfermedad infecciosa o el rebrote se propaga a } \\
\text { otras regiones del país tras su llegada desde el extranjero. }\end{array}$ & $\begin{array}{l}\text { Sistema de respuesta en } \\
\text { operación (oficina central dirigida } \\
\text { por el MSB). }\end{array}$ \\
\hline $\begin{array}{l}\text { Nivel 4: } \\
\text { Seriedad } \\
\text { (rojo) }\end{array}$ & $\begin{array}{l}\text { Señales de propagación global de la nueva enfermedad } \\
\text { infecciosa; señales de propagación nacional en Corea de } \\
\text { la nueva enfermedad infecciosa; señales de propagación } \\
\text { nacional de rebrote de enfermedad infecciosa. }\end{array}$ & $\begin{array}{l}\text { Movilización total de } \\
\text { capacidades de respuesta } \\
\text { (oficina central dirigida por el } \\
\text { primer ministro). }\end{array}$ \\
\hline
\end{tabular}

Fuente: Ministerio de Salud y Bienestar de Corea del Sur (2014: 8).

enfermedad, su velocidad de desarrollo, duración y propagación, la opinión pública y la capacidad de respuesta del gobierno (cuadro 1).

El 3 de enero de 2020, cuando la enfermedad infecciosa ya se extendía en el mundo, el gobierno coreano estableció el nivel de alerta azul (nivel 1), el primero de los cuatro grados del sistema nacional de gestión de crisis. El 20 de enero de 2020 se elevó la alerta nacional a amarillo (nivel 2), porque la nueva enfermedad infecciosa (covid-19) había logrado penetrar Corea y se notificaba su primera aparición en el país (Gobierno de la República de Corea, 2020a). El gobierno coreano elevó el nivel de alerta de amarillo (nivel 2) a naranja (nivel 3) el 28 de enero de 2020, debido a que el covid-19 se había extendido a otras regiones de Corea. La Oficina Central de Manejo de Desastres se reunió, presidida por el ministro de salud y bienestar, para dirigir la respuesta. Adicionalmente, cada gobierno local formó sus propios equipos de desastre y seguridad, dirigidos por el jefe del gobierno local, con el fin de conseguir camas de hospital y gestionar los hospitales locales.

El 23 de febrero de 2020, el nivel de alerta nacional se elevó de naranja (nivel 3) a rojo (nivel 4), debido a señales de propagación de la nueva enfermedad infecciosa en todo el mundo y dentro de Corea. Ante este hecho, el gobierno reunió 
a la Oficina Central de Medidas de Seguridad contra Desastres (OCMSD), encabezada por el primer ministro, para reforzar la respuesta de todo el gobierno contra el covid-19 (cuadro 1). Así, el primer ministro se convirtió en comandante en jefe de la lucha contra el covid-19, con el apoyo total del presidente. En otras palabras, los mecanismos institucionales de gestión de desastres y la voluntad política tuvieron una respuesta lo más rápida y enérgica posible ante la pandemia.

Dada la naturaleza particular y la experiencia profesional requeridas para responder a una enfermedad infecciosa, el Centro de Control y Prevención de Enfermedades de Corea del Sur (СCPE), bajo el mando del MSB, es el eje para la prevención y el control de ese tipo de enfermedades. El CCPE se divide en varios centros de investigación, institutos y oficinas, así como en muchas instalaciones nacionales de cuarentena en varias zonas locales (CCPE, 2020). El CCPE ha sido un organismo operativo crucial en la respuesta diaria al covid-19, sus funciones organizacionales han sido mejoradas y, en septiembre de 2020, fue renombrado como Agencia de Control y Prevención de Enfermedades de Corea (ACPE).

La rápida respuesta coreana al covid-19 es resultado de las cicatrices del pasado. Thompson (2020) afirma que la respuesta exitosa no es producto de ningún destino religioso ni cultural. El aprendizaje propiciado por las crisis anteriores le permitió a Corea responder con efectividad a la pandemia del coronavirus. Edward Deverell (2009) afirma que el aprendizaje organizacional inducido por una crisis es resultado de esfuerzos conscientes desatados por la crisis, y llevados a cabo por miembros de una organización que trabaja dentro de una comunidad de investigación. Tales esfuerzos llevan a un nuevo entendimiento de las crisis y, en consecuencia, a un nuevo comportamiento respecto a ellas. De hecho, Corea aprendió las lecciones de desastres previos, como el naufragio del Sewol y el brote del Síndrome Respiratorio de Oriente Medio (MERs, por sus siglas en inglés) (Kim, 2020): el desastre del naufragio del Sewol sucedió en 2014 y tomó la vida de 304 personas (Kim y Lee, 2014: 506-527), mientras que el brote del MERs se dio en 2015 y murieron 38 personas.

A partir de estos dos desastres, Corea aprendió de la manera difícil la importancia de la preparación. Después del naufragio del Sewol, el gobierno coreano comprendió que, en caso de un accidente importante, los jefes de organismos públicos relacionados, así como los principales líderes del país deben estar alerta y movilizar todos los medios posibles para hacer frente a la situación lo más rápido posible. En el caso del MERs, no hubo participación público-privada ni sistema de aprobación de emergencia para equipos de diagnóstico, además de que la unidad responsable de enfermedades infecciosas era débil. Tras esta segunda ex- 
periencia, varias medidas de salud y cuarentena comenzaron a tomarse en serio. En otras palabras, el aprendizaje propiciado por crisis previas es posible cuando las lecciones se incorporan a las estructuras y sistemas de la organización pública y, por lo tanto, influyen en la gestión de crisis subsecuentes (Deverell, 2009).

\section{MEDIDAS DE SALUD Y CUARENTENA PARA EL CONTROL DE ENFERMEDADES INFECCIOSAS}

Las políticas gubernamentales contra el covid-19 suelen variar entre regiones dentro de cada país. El Rastreador de Respuestas Gubernamentales del covid-19 de Oxford (Hale et al., 2020) codificó las políticas públicas más estrictas que se han implementado en diversos países y las organizó en cuatro grupos: políticas de contención y cierre, políticas económicas, políticas sanitarias y políticas mixtas. En este artículo no podemos hablar de todas, así que nos limitaremos a las principales políticas sanitarias relacionadas con la crisis del coronavirus en Corea.

Mientras que muchos países de América, Europa, Asia y Medio Oriente presentan cifras elevadas de casos confirmados y muertes, el conteo de casos y muertes en Corea es comparativamente bajo (Worldometer, 2021). En consecuencia, Corea ha atraído la curiosidad internacional sobre el tipo de respuestas del gobierno y las razones por las que en Corea se han presentado menos casos confirmados y muertes. Las medidas de salud y cuarentena que tomó el gobierno coreano se pueden resumir en tres pilares: 1) la producción de equipos de pruebas y diagnósticos generalizados; 2) el uso de tecnologías de la información y comunicación (TIC), rastreo intenso de contactos y aislamiento, y 3) clasificación de los síntomas y tratamiento efectivo a los pacientes, como se muestra en el cuadro 2. En otras palabras, el gobierno coreano implementó estrategias de prueba-rastreo-aislamiento-tratamiento para hacer pruebas a las personas con síntomas de coronavirus, rastrear a sus contactos, aislar a los casos positivos y tratar a los pacientes con efectividad.

\section{Producción de equipos de pruebas y diagnósticos generalizados}

Una semana después de que se confirmara el primer caso en Corea, el 27 de enero de 2020, los funcionarios del CCPE se reunieron con representantes de la Asociación de Laboratorios Médicos de Corea y con varios productores biofarmacéuticos para hablar sobre los equipos de pruebas. La reunión se cuenta entre las primeras acciones importantes que tomó el gobierno coreano como respuesta a la pandemia del covid-19. Los funcionarios del CCPE compartieron información sobre la enfermedad con todos los participantes y alentaron la producción de pruebas con- 
CUADRO 2. Medidas de salud y cuarentena para el control de enfermedades en Corea

\begin{tabular}{|c|c|c|c|}
\hline Enfoque & Contenido & Métodos clave & Principales participantes \\
\hline $\begin{array}{l}\text { Producción } \\
\text { de equipos de } \\
\text { pruebasy } \\
\text { diagnósticos } \\
\text { generalizados }\end{array}$ & $\begin{array}{l}\text { Producción de equipos de } \\
\text { pruebas y uso de pruebas de } \\
\text { diagnóstico; establecimiento } \\
\text { de kioscos de pruebas } \\
\text { para acudir a pie o en } \\
\text { automóvil, en cooperación } \\
\text { con hospitales públicos y } \\
\text { privados y clínicas locales }\end{array}$ & $\begin{array}{l}\text { - Técnicas de diagnóstico grupal } \\
\text { por amplificación génica } \\
\text { - Métodos de reactivos y pruebas } \\
\text { relacionados con técnicas de } \\
\text { diagnóstico } \\
\text { - Pruebas a casos sospechosos, } \\
\text { grupos de alto riesgo, etc. }\end{array}$ & $\begin{array}{l}\text { Funcionarios públicos } \\
\text { del sector salud, } \\
\text { expertos en diagnósticos } \\
\text { de enfermedades } \\
\text { infecciosas, productores } \\
\text { de reactivos, de } \\
\text { equipos de prueba } \\
\text { y equipamiento } \\
\text { relacionado }\end{array}$ \\
\hline $\begin{array}{l}\text { Uso de TIC, } \\
\text { rastreo intenso } \\
\text { de contactosy } \\
\text { aislamiento }\end{array}$ & $\begin{array}{l}\text { Investigación epidemiológica } \\
\text { activa para obtener } \\
\text { información sobre atención } \\
\text { médica y de actividad de los } \\
\text { casos sospechosos a partir } \\
\text { de los teléfonos celulares; } \\
\text { cuarentena o aislamiento de } \\
\text { pacientes tras confirmación }\end{array}$ & $\begin{array}{l}\text { - Uso de TIC e inteligencia artificial } \\
\text { (IA) } \\
\text { - Uso de aplicaciones móviles } \\
\text { de autodiagnóstico } \\
\text { - Uso de aplicación móvil para } \\
\text { la gestión de la cuarentena } \\
\text { y el aislamiento durante dos } \\
\text { semanas a personas guardando } \\
\text { cuarentena en solitario } \\
\text { - Método de cruzado de registros } \\
\text { médicos electrónicos, etc. }\end{array}$ & $\begin{array}{l}\text { Funcionarios públicos } \\
\text { del sector salud, } \\
\text { diseñadores de } \\
\text { aplicaciones móviles } \\
\text { de autodiagnóstico y } \\
\text { aislamiento, gerentes } \\
\text { de información médica, } \\
\text { expertos en datos de } \\
\text { movilidad }\end{array}$ \\
\hline $\begin{array}{l}\text { Clasificación } \\
\text { de síntomas } \\
\text { y tratamiento } \\
\text { efectivo para } \\
\text { los pacientes }\end{array}$ & $\begin{array}{l}\text { Clasificación basada en la } \\
\text { gravedad de los síntomas de } \\
\text { los pacientes diagnosticados; } \\
\text { los pacientes graves se } \\
\text { admiten en el hospital,y } \\
\text { los no muy graves se tratan } \\
\text { en centros públicos }\end{array}$ & $\begin{array}{l}\text { - Operación de hospitales, } \\
\text { clínicas e instalaciones públicas } \\
\text { para enfermedades infecciosas } \\
\text { - Asignación de camas con base } \\
\text { en la gravedad de los síntomas } \\
\text { de los pacientes } \\
\text { - Uso de normas (de } \\
\text { distanciamiento social, de } \\
\text { higiene personal, de prevención } \\
\text { de infecciones, etc.) }\end{array}$ & $\begin{array}{l}\text { Expertos en tratamientos } \\
\text { médicos (personal } \\
\text { médico y de enfermería), } \\
\text { operadores de hospitales } \\
\text { públicos, privados y } \\
\text { clínicas, y gestores de } \\
\text { bienestar social }\end{array}$ \\
\hline
\end{tabular}

Fuente: Elaboración propia.

fiables. A los productores de equipos de diagnóstico se les dijo que estaba en camino la "autorización de uso de emergencia" (un sistema de aprobación rápida) para tales equipos, y que debían apresurar su desarrollo.

Poco tiempo después, una compañía biofarmacéutica coreana (KogeneBiotech) desarrolló un equipo de diagnóstico de covid-19 que usaba TIC, IA y alta tecnología computacional (KogeneBiotech, 2020). Gracias a estos equipos, los especialistas coreanos en análisis de imágenes médicas con IA detectaron elementos anormales, como neumonía — un síntoma importante entre pacientes de covid-19—, 
con un alto grado de precisión y rapidez (Kim y Hong, 2017). Los equipos de diagnóstico pronto estuvieron disponibles a través de varias otras compañías y desempeñaron un papel central en eliminar incertidumbres durante las primeras fases de la propagación viral. Corea usa pruebas de ácido nucleico (reacción en cadena de la polimerasa en tiempo real [RT-PCR]) para diagnosticar pacientes. Médicos, enfermeros y científicos de laboratorios clínicos recolectan muestras en ubicaciones específicas, como kioscos de pruebas accesibles a pie o en coche. Posteriormente, los laboratorios hacen diagnósticos exhaustivos en el menor periodo de tiempo posible para asegurar la detección temprana de los pacientes, lo que minimiza la propagación del virus.

El gobierno coreano estableció estaciones de evaluación en centros e instituciones de salud públicos para asegurar un acceso más fácil a las pruebas de diagnóstico y un control efectivo de la infección. Los kioscos de pruebas accesibles a pie o en automóvil se iniciaron en Corea y, desde entonces, se han adoptado en todo el mundo. Los kioscos de pruebas son un brillante ejemplo de una idea innovadora, su objetivo es hacer pruebas a personas sospechosas de portar la infección cuando aparecen síntomas como tos y fiebre, antes de admitirlos en una institución de salud. Para el 7 de mayo de 2020, había en operación un total de 638 kioscos de pruebas (ocmsD, 2020) y su número se incrementó en el otoño del mismo año. Estas instalaciones están disponibles para que todos los residentes que sospechen haber contraído el covid-19 (incluidos trabajadores migrantes ilegales) puedan hacerse una prueba gratuita sin miedo inmediato de sufrir sanciones legales. Actualmente, cualquier persona puede tomar una prueba diagnóstica en una estación pública local de pruebas sin restricciones y de manera gratuita. Hay un total de 118 laboratorios e instituciones (CCPE, Estaciones Nacionales de Cuarentena, Institutos de Investigación de Salud Pública y Medio Ambiente, y laboratorios y hospitales privados) disponibles para procesar las pruebas de diagnóstico, y los resultados se entregan el mismo día (Gobierno de la República de Corea, 2020c).

\section{Uso de TIC, rastreo intenso de contactos y aislamiento}

Corea desarrolló con rapidez un sistema para realizar pruebas gratuitas diarias, al tiempo que se apoyó en aplicaciones móviles y tecnología de GPS para rastrear casos, lo cual le dio los instrumentos para aplastar rápidamente cualquier nuevo brote. El gobierno coreano usa ampliamente las TIC para evitar la propagación del covid-19. Un ejemplo es la aplicación móvil de autodiagnóstico que monitorea los síntomas de los viajeros que entran al país y les ofrece asesoría médica 
oportuna. Además, el gobierno desarrolló una aplicación de protección para la gente que está sola en cuarentena. La aplicación móvil monitorea con eficacia a dichos individuos durante dos semanas y les pide que reporten sus síntomas (temperatura, tos, dolor de garganta y disnea) dos veces al día (Gobierno de la República de Corea, 2020b).

Asimismo, el Ministerio de Tierra, Infraestructura y Transporte (2020), en cooperación con el CCPE y el Ministerio de Ciencia y Tecnología, desarrolló el sistema de apoyo a la investigación epidemiológica para el covid-19, que automatiza dichas investigaciones. Una vez piloteado el sistema, el 16 de marzo de 2020, se puso bajo control del CCPE y empezó a operar oficialmente el 26 de marzo de 2020 (Gobierno de la República de Corea, 2020b). Este sistema redujo de manera significativa el tiempo necesario para rastrear contactos: se pasó de varias horas de recopilar y analizar datos manualmente a un proceso informático de solo 10 minutos, pues se computarizaron y automatizaron los datos agregados, de GPS y transacciones de tarjetas de crédito (Gobierno de la República de Corea, 2020c). Así, podemos decir que su éxito ha dependido, en gran medida, de su capacidad y velocidad para ampliar las soluciones tecnológicas.

El gobierno coreano introdujo varios métodos de investigación epidemiológica para reforzar la precisión de las investigaciones y superar las limitaciones de las entrevistas a pacientes, que dependen de la memoria y la honestidad de los mismos. Esta medida encontró apoyo legal en la enmienda de la Ley de Control y Prevención de Enfermedades Infecciosas (LCPEI), según la cual las autoridades de la cuarentena en Corea no sólo usan las declaraciones de los pacientes, sino también información personal a través de rastreo de ubicación y transacciones de tarjetas de crédito para identificar con precisión las transmisiones. Para asegurar su prontitud, las investigaciones epidemiológicas principales para casos individuales están a cargo de expertos de rastreo de los gobiernos locales. Para los brotes dentro de las instituciones de salud e instalaciones que albergan grupos de personas, se envía al equipo de respuesta a emergencias del CCPE con el fin de hacer investigaciones epidemiológicas basadas en datos, en colaboración con las unidades de gestión de enfermedades infecciosas de cada gobierno local a cargo (Gobierno de la República de Corea, 2020b).

\section{Clasificación de síntomas y tratamiento efectivo en pacientes}

Es efectivo clasificar a los pacientes en graves y no graves para su atención, pues ayuda a tratar a una gran cantidad de personas confirmadas en un menor tiempo. Con base en esta premisa, los pacientes de covid-19 se clasifican en cuatro cate- 
gorías, según la gravedad de su condición: no graves, moderados, graves y muy graves. Las personas que pertenecen a algún grupo de riesgo (ancianos, personas con condiciones crónicas subyacentes, pacientes que toman algún medicamento inmunosupresor y mujeres embarazadas) se clasifican como pacientes graves sin importar sus síntomas clínicos, para que puedan recibir cuidados oportunos si los requieren.

Los pacientes con condiciones moderadas, graves o muy graves son admitidos en hospitales con amplia capacidad de tratamiento. Este sistema permite que los pacientes reciban los cuidados necesarios de manera oportuna. El covid-19 está catalogada como una enfermedad infecciosa de primera categoría, por lo que los costos de las pruebas y del tratamiento médico deben ser absorbidos totalmente por el Estado, de acuerdo con la LCPEI. Por ejemplo, el costo de medicamentos como el Remdesivir, reconocido para tratar el covid-19, también es con cargo al erario. Cuando los pacientes mejoran, se dan de alta según los estándares de alta con aislamiento. En Corea, 74 hospitales han sido designados como hospitales covid-19, y hay más de 7500 camas disponibles por si se presentara un incremento de los casos (ocmsd, 2020).

Los pacientes no graves son enviados a centros públicos de tratamiento designados por los gobiernos locales. Aunque estos no son hospitales, cuentan con personal médico residente que revisa con regularidad la salud de los infectados y los hospitaliza según los diagnósticos del cuerpo médico a cargo. A los contactos asintomáticos de los casos recién diagnosticados se les pide guardar cuarentena aislados en casa y que usen baños, platos y toallas distintos a los de sus convivientes. Los funcionarios de los servicios de salud monitorean sus síntomas dos veces al día (Thompson, 2020).

El 13 de enero de 2021, Celltrion Group, una de las principales empresas biofarmacéuticas coreanas, anunció datos positivos de eficacia y seguridad de su ensayo clínico global a doble ciego y controlado con placebo de fase II/III del CT-P59, un candidato a tratamiento con anticuerpos monoclonales contra el covid-19. En la primera fase del ensayo se reclutaron a 327 pacientes con síntomas leves a moderados de covid-19 en tres grupos de tratamiento $(40 \mathrm{mg} / \mathrm{kg}, 80 \mathrm{mg} /$ $\mathrm{kg}$ y placebo), en los cuales aproximadamente 60 por ciento de quienes presentaban síntomas moderados sufría neumonía relacionada con covid-19 (Celltrion Group, 2021). Este desarrollo farmacéutico podría mejorar el acceso a opciones de tratamiento eficaces para quienes las necesitan.

En cuanto a las vacunas, Corea firmó un acuerdo con AstraZeneca en diciembre de 2020, para asegurar 20 millones de dosis de su vacuna, y se espera que el 
primer envío sea en enero de 2021 (Shin y Cha, 2020). Corea también tiene acuerdos con otros tres fabricantes de medicamentos, entre ellos Pfizer, Janssen de Johnson \& Johnson, y la iniciativa mundial de Fondo de Acceso Global para Vacunas Covid-19 (Covax), respaldada por la Organización Mundial de la Salud (OMS). Además, la empresa biotecnológica estadounidense Moderna suministrará a Corea dosis suficientes de su vacuna para 20 millones de personas a partir del segundo trimestre de 2021. Desde el 19 de enero de 2021, el país ha conseguido 106 millones de dosis para permitir la cobertura de 56 millones de personas, más de los 52 millones de residentes en el país. Las autoridades planean iniciar la vacunación en febrero de 2021, inoculando a los trabajadores sanitarios y la población vulnerable en primer lugar.

\section{DISCUSIÓN SOBRE LA GOBERNANZA COLABORATIVA}

La guerra contra el covid-19 es difícil de resolver a través de un solo organismo como el gobierno central o el local, por lo tanto la colaboración entre ambos es vital en esta lucha. La colaboración permite al gobierno central trabajar con las autoridades locales para detener la propagación del virus entre comunidades, mediante el intercambio de información vital sobre la cuarentena (incluidos datos sobre casos confirmados e historiales de viajes), la imposición de sistemas de cuarentena para redes de transporte intra e interurbano y la compartición de camas entre hospitales para personas infectadas, si es necesario. Los gobiernos de todos los niveles han participado en la resolución de problemas asociados con la pandemia de covid-19; el sector privado también ha colaborado a través de hospitales privados, industrias médicas y biofarmacéuticas, y asociaciones profesionales involucradas en el campo de las enfermedades infecciosas, como se muestra en el cuadro 2. En particular, se ha dado prioridad a las opiniones de expertos epidemiólogos al lidiar con la pandemia.

Ansell y Gash (2008: 543-571) afirman que la gobernanza colaborativa lleva al gobierno, la comunidad y el sector privado a trabajar juntos para lograr más de lo que podría haber alcanzado uno de esos sectores actuando por separado. Así, la respuesta del gobierno coreano a la pandemia podría ser un ejemplo interesante de gobernanza colaborativa (Ansell y Gash, 2008: 543-571; Emerson et al., 2012: 1-29). Una crisis obliga a los gerentes públicos a colaborar más de cerca en distintas redes o en redes ad hoc, formadas por actores estatales y no estatales (Van der Wal, 2020).

La OCMSD, encabezada por el primer ministro, ofrece apoyo pangubernamental de manera eficiente. El primer ministro, comandante en jefe de la lucha 
contra el covid-19, preside reuniones interministeriales con ministerios y agencias relacionados y coopera con los gobiernos locales. En la gestión diaria para el control y prevención de la enfermedad a nivel profesional, el CCPE maneja todas las medidas de prevención y control de la infección, con el propósito de responder con eficiencia a la crisis.

Además, todos los gobiernos locales han establecido equipos locales de prevención de desastres y seguridad (cada uno presidido por su respectivo alcalde o gobernador) para movilizar todas las capacidades posibles de prevención y control de la infección. En otras palabras, varios gobiernos locales, incluidos los provinciales y municipales, han creado un nuevo departamento de gestión de enfermedades infecciosas.

Asimismo, la asociación con empresas privadas ha sido una estrategia importante para que el gobierno controle la crisis sanitaria, en términos de pruebas, rastreo y tratamiento. Como se mencionó anteriormente, el CCPE se comunicó con las empresas médicas, pidiéndoles que desarrollaran equipos de pruebas y prometiéndoles la aprobación de emergencia. En Corea, una gran proporción de hospitales pertenece a particulares, por lo que las asociaciones con el sector privado han ayudado al gobierno a realizar pruebas, rastreos y tratamientos eficaces para controlar la pandemia de covid-19.

Por lo anterior, es evidente que los esfuerzos gubernamentales en todos los niveles han tenido un papel central en la estabilización del tratamiento de los pacientes infectados, junto con la colaboración con varios socios de los sectores público y privado.

\section{CONCLUSIÓN E IMPLICACIONES DE POLÍTICA PÚBLICA}

Las principales respuestas del gobierno coreano a la pandemia del coronavirus se pueden resumir en tres elementos centrales: 1) la producción de equipos de pruebas y diagnósticos generalizados; 2) el uso de TiC y el rastreo intensivo de contactos, y 3) la clasificación de los síntomas de los pacientes y el tratamiento efectivo de los infectados (Kim, 2020). La rápida expansión de las pruebas y el rastreo en Corea, así como el uso de la tecnología, ayudaron a aplanar la curva de la propagación del covid-19. En una línea similar, hace algunos años, la oms (2012) lanzó una iniciativa contra la malaria llamada "T3" (test, treat, track), urgiendo a donantes, a la comunidad global y a los países donde dicha enfermedad es endémica a aumentar las pruebas de diagnóstico, el tratamiento y la supervisión de la enfermedad con base en lo siguiente: $a$ ) debe hacerse una prueba a cada caso sospechoso de malaria; b) cada caso confirmado se debe tratar con 
una medicina de calidad comprobada contra la malaria, y c) se debe rastrear la enfermedad mediante un sistema de supervisión oportuno y preciso. Parece que el gobierno coreano fue efectivo al aplicar una estrategia similar para hacer frente a la pandemia del coronavirus. Con ello, el gobierno coreano puso en marcha la realización de pruebas a las personas que presentaban síntomas de coronavirus, rastreó a sus contactos, puso en aislamiento a quienes daban positivo y trató eficazmente a los pacientes enfermos. Sin embargo, es importante señalar que Corea no estableció un sistema de pruebas y rastreo de la noche a la mañana. La respuesta al brote actual forma parte de un plan fuertemente respaldado con recursos financieros y desarrollado durante años como respuesta a fracasos experimentados en epidemias anteriores.

Otro rasgo importante de la experiencia coreana son los esfuerzos proactivos del gobierno para colaborar con varios socios; tales esfuerzos podrían ser un buen ejemplo de gobernanza colaborativa (Ansell y Gash, 2008: 543-571; Emerson et al., 2012: 1-29). La estrategia de pruebas y rastreo estuvo apoyada por un sistema de salud apropiadamente financiado y por gobiernos locales activos. Aunque el sistema hospitalario coreano está fuertemente privatizado, el gobierno ha colaborado muy de cerca con varios socios. Además, el apoyo legal para acciones administrativas se fortaleció de manera oportuna, lo que contribuyó a reforzar la respuesta del gobierno a la pandemia. Por ejemplo, las leyes sobre prevención y manejo de enfermedades infecciosas y sobre cuarentena se revisaron en marzo de 2020 (Kim, 2020).

Para lidiar con la pandemia de manera más efectiva, el gobierno coreano amplió la capacidad del CCPE para convertirlo en un centro de control de enfermedades más eficaz, mediante la revisión de la Ley de Organización Gubernamental efectuada por la Asamblea Nacional el 4 de agosto de 2020. En consecuencia, el CCPE se transformó en la ACPE, y se convirtió así en el eje de control de todos los brotes infecciosos, adquiriendo mayor autoridad profesional en las emergencias sanitarias. De manera similar, en el Reino Unido, según una declaración del Departamento de Salud y Asistencia Social (DSAS) de ese país, el Instituto Nacional de Protección a la Salud (INPS) remplazará a la Agencia de Salud Pública de Inglaterra (ASPI), siguiendo los ejemplos de Corea y Alemania, y tratando de mejorar la respuesta del Reino Unido a la pandemia en curso (Pym, 2020). Bajo el nuevo organismo, la ASPI y el Servicio Nacional de Salud para Prueba y Rastreo se unirán, junto con el Centro Conjunto de Bioseguridad, bajo un solo equipo directivo (Departamento de Salud y Asistencia Social del Reino Unido, 2020). 
Con base en la experiencia coreana, podemos extraer las siguientes implicaciones de política pública. Primero, la pandemia del coronavirus ha provocado una crisis económica sin precedentes. El papel del gobierno está cambiando y sería difícil para las autoridades manejar la actual crisis con medidas de austeridad neoliberal. Sin embargo, las metas económicas se subordinan en momentos de crisis, debido a que la gente se enfoca en la emergencia cotidiana de sobrevivir. Quizá sea muy temprano para saber cuál será el saldo final de la pandemia, pero existe un riesgo real de una severa recesión económica, así que el gobierno tiene que tomar medidas de gran alcance para impulsar intensivamente la demanda interna y el consumo, y recuperar la estabilidad económica.

En segundo lugar, en el proceso de superar la enfermedad del coronavirus, es importante asegurar la protección de los grupos socialmente desaventajados. La asistencia gubernamental debe atender principalmente a los que han sufrido más, y asegurarse de que los individuos y negocios vulnerables resistan la crisis. Robert Reich (2020) afirma que están surgiendo cuatro nuevas clases de trabajadores: los remotos, los esenciales, los no pagados y los olvidados, lo que crea una nueva división estamental; además, estas clases se infectan de manera desproporcionada. En épocas difíciles, por lo tanto, la prioridad debería ser proteger a los trabajadores que estén en el umbral del desempleo y apoyar a la gente más vulnerable.

Finalmente, la resiliencia adquiere cada vez más importancia de cara al covid-19, porque es necesaria para ayudar a las organizaciones públicas a absorber turbulencias y choques, y a adaptarse a los nuevos retos. En años recientes, se ha prestado mayor atención a la resiliencia como la capacidad de las organizaciones y los individuos para recuperarse ante una perturbación (Comfort et al., 2010; Boin y Van Eeten, 2013: 429-445). Sin embargo, dicha resiliencia suele estar construida sobre cimientos débiles. Así, es necesario realizar investigaciones más amplias para asegurar un mayor desarrollo de la resiliencia organizacional e individual. G으

\section{REFERENCIAS}

Ansell, C. y A. Gash (2008), "Collaborative Governance in Theory and Practice", Journal of Public Administration Research and Theory, 18(4), pp. 543-571.

Boin, A. y M.J.G. Van Eeten (2013), "The Resilient Organization: A Critical Appraisal”, Public Management Review, 15(3), pp. 429-445.

CCPE (Centro de Control y Prevención de Enfermedades de Corea del Sur) (2020), Middle East Respiratory Syndrome (MERS), Sejong, Centro de Control y Prevención de Enfermedades, disponible en: http://www.cdc.go.kr/contents.es?mid=a30301100000 [fecha de consulta: 15 de mayo de 2020]. 
Celltrion Group (2021), "Celltrion Group Announces Positive Top-line Efficacy and Safety Data from Global Phase II/III Clinical Trial of COVID-19 Treatment Can-didate CT-P59", disponible en: https://www.celltrionhealthcare.com/en-us/board/ newsdetail?modify_key=433\&pagenumber $=1 \&$ keyword=\&keyword_type $=[$ fecha de consulta: 13 de enero de 2021].

Choe, S. (2020), "In South Korea Vote, Virus Delivers Landslide win to Governing Party", New York Times, disponible en: https:/www.nytimes.com/2020/04/15/world/asia/ south-korea-election.html [fecha de consulta: 30 de julio de 2020].

Comfort, L.K., A. Boin y C.C. Demchak (eds.) (2010), Designing Resilience: Preparing for Extreme Events, Pittsburgh, University of Pittsburgh Press.

Departamento de Salud y Asistencia Social del Reino Unido (2020), The Future of Public Health: The National Institute for Health Protection and other Public Health Functions, disponible en: https://www.gov.uk/government/publications/the-future-of-publichealth-the-nihp-and-other-public-health-functions/the-future-of-public-health-thenational-institute-for-health-protection-and-other-public-health-functions [fecha de consulta: 20 de agosto de 2020].

Deverell, E. (2009), "Crises as Learning Triggers: Exploring a Conceptual Framework of CrisisInduced Learning”, Journal of Contingencies and Crisis Management, 17(3), pp. 179-188.

Emerson, K., T. Nabatchi y S. Balogh (2012), "An Integrative Framework for Collaborative Governance", Journal of Public Administration Research and Theory, 22(1), pp. 1-29.

Farazmand, A. (ed.) (2014), Crisis and Emergency Management: Theory and Practice, $2^{\mathrm{a}} \mathrm{ed}$., Londres, Routledge.

Gobierno de la República de Corea (2020a), Tackling COVID-19, Seúl, Gobierno de la República de Corea.

Gobierno de la República de Corea (2020b), How Korea Responded to a Pandemic Using ICT: Flattening the Curve on COVID-19, Seúl, Gobierno de la República de Corea.

Gobierno de la República de Corea (2020c), COVID-19, Testing Time for Resilience: In Recovering from COVID-19: Korean Experience, Seúl, Gobierno de la República de Corea. Hale, T., S. Webster, A. Petherick, T. Phillips y B. Kira (2020), Oxford COVID-19 Government Response Tracker, Oxford, Blavatnik School of Government, disponible en: https:// github.com/OxCGRT/covid-policy-tracker/blob/master/documentation/codebook. md [fecha de consulta: 15 de julio de 2020].

Kim, P.S. (2020), "South Korea's Fast Response to Coronavirus Disease: Implications on public policy and Public Management Theory", Public Management Review, 22, DoI: 10.1080/14719037.2020.1766266.

Kim, P.S. y K.P. Hong (2017), "Debate: Humanized Robotic Agents in Government-The Emergence of the Hubogent”, Public Money and Management, 37(2), pp. 131-132. 
Kim, P.S. y J.E. Lee (2014), “Crisis and Emergency Management in Korea”, en A. Farazmand (ed.), Crisis and Emergency Management: Theory and Practice, $2^{\mathrm{a}}$ ed., Londres, Routledge, pp. 506-527.

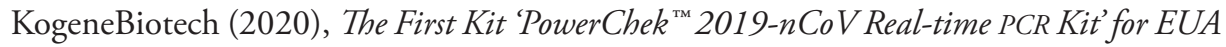
by KFDA \& KCDC, Seúl, KogeneBiotech, disponible en: http://www.kogene.co.kr/eng/ sub/customer/notice_view.asp?idx=503 [fecha de consulta: 11 de febrero de 2020].

Ministerio de Salud y Bienestar de Corea del Sur (2014), The Standard Manual for Crisis Management on Infectious Disease, Sejong, Ministerio de Salud y Bienestar.

Ministerio de Salud y Bienestar de Corea del Sur (2021), Coronavirus Disease-19 in the Republic of Korea, Sejong, Ministerio de Salud y Bienestar, disponible en: http://ncov. mohw.go.kr/en/ [fecha de consulta: 19 de enero de 2021].

Ministerio de Tierra, Infraestructura y Transporte de Corea del Sur (2020), Media briefing: COVID-19 Smart Management System, 10 de abril, Ministerio de Tierra, Infraestructura y Transporte, disponible en: http://molit.go.kr/USR/NEWS/m_71/dtl.jsp?id=95083773 [fecha de consulta: 10 de abril de 2020].

ocmsd (Oficina Central de Medidas de Seguridad contra Desastres) (2020), Korea's Response to COVID-19 and Future Direction, Seúl, Oficina Central de Medidas de Seguridad contra Desastres de Corea del Sur.

oms (Organización Mundial de la Salud) (2012), T3: Test. Treat. Track Initiative, Ginebra, oms, disponible en: https://www.who.int/malaria/areas/test_treat_track/en/ [fecha de consulta: 1 de agosto de 2020].

Pym, H. (2020), "Coronavirus: Public Health England to be Replaced”, BBC, 17 de agosto, disponible en: https:/www.bbc.com/news/health-53799854 [fecha de consulta: 19 de agosto de 2020].

Reich, R. (2020), "Coronavirus is Creating a New Class Divide that Threatens Us All”, Newsweek, 28 de abril, disponible en: https://www.newsweek.com/robert-reich-coronavirus-creating-new-class-divide-that-threatens-us-all-opinion-1500506 [fecha de consulta: 20 de mayo de 2020].

Shin, H. y S. Cha (2020), "South Korea to Buy Millions of Coronavirus Vaccine Doses but Sees no Need to Hurry", Reuters, 8 de diciembre, disponible en: https://www.reuters. com/article/us-health-coronavirus-southkorea/south-korea-to-buy-millions-of-coronavirus-vaccine-doses-but-sees-no-need-to-hurry-idUSKBN28I053 [fecha de consulta: 8 de diciembre de 2020].

Thompson, D. (2020), “What's behind South Korea’s COVID-19 Exceptionalism?”, Atlantic, 6 de mayo, disponible en: https://theatlantic.com/ideas/archive/2020/05/whatssouth-koreas-secret/611215/ [fecha de consulta: 11 de mayo de 2020].

Van der Wal, Z. (2020), "Being a Public Manager in Times of Crisis: The Art of Managing 
Stakeholders, Political Masters, and Collaborative Networks", Public Administration Review, 80(5), pp. 759-764.

Worldometer (2021), Covid-19 Coronavirus Pandemic, disponible en: https://worldometers. info/coronavirus/ [fecha de consulta: 19 de enero de 2021].

Pan Suk Kim es profesor de Administración Pública en la Facultad de Gobierno y Negocios de la Universidad de Yonsei (Corea del Sur). Actualmente es miembro de la Comisión Internacional del Servicio Civil de las Naciones Unidas, director internacional de la American Society for Public Administration (ASPA) y miembro vitalicio de la Academia Nacional de Administración Pública de Washington, D.C. Fue presidente del Instituto Internacional de Ciencias Administrativas y de la Asociación Asiática de Administración Pública. 